\title{
LA CAPILLA DEL SEÑOR DE CONTRERAS EN EL CARMEN DE SAN ANGEL Y LAS PINTURAS DE LUIS JUAREZ
}

\author{
José Rogelio Ruiz Gomar C.
}

El 13 de agosto del año de 1935 un incendio destruyó la capilla del Señor de Contreras, anexa a la iglesia de El Carmen de San Ángel. En poco tiempo quedó reducida a escombros y cenizas la riqueza artística ahi reunida por las generaciones pasadas: los enormes lienzos al óleo que la cubrían y la madera tallada y dorada de los retablos que en ella paraban, sirvieron de excelente alimento a las implacables llamas que, al final, todo lo consumieron.

Empero, lo ignominioso del caso es que, al parecer, ni siquiera cabe para tan lamentable suceso la torpe disculpa de haber sido un accidente, por más que se haya manejado la versión de que todo fue ocasionado por un problema en las instalaciones del suministro de la energía eléctrica, ${ }^{1}$ ya que según otras versiones que circularon en la época, el fuego fue provocado intencionalmente. $Y$ aunque nunca se llegaron a aclarar satisfactoriamente las razones que motivaron tan alevosa cuanto innecesaria profanación -se dijo, por ejemplo, que el incendio había sido producido para disimular el robo de unas pinturas-, se propaló un insistente rumor que hacía responsable del atentado a la "satánica rabia" y a "la primitiva barbarie de un grupo de comunistas", que con la complacencia de ciertas autoridades, habían destruido lo que no eran sino obras levantadas por la fe. ${ }^{2}$

Aunque igualmente punible, prefeririamos creer que efectivamente todo fue un accidente; pero de ser cierta esta última versión, tan infame crimen viene a ser prueba no sólo del fanatismo a que también suelen conducir los inflamados ideales políticos y los extremos ideológicos, sino más particularmente de la estulticia y ceguera a que puede llegar el hombre que no sabe respetar las creencias religiosas de los

1 De ella se hace eco don Francisco de la Maza cuando expresa: "Lo que no pasó nunca en la época virreinal (salvo un caso), ni en el sigio xIx, ha sucedido en ei $\mathrm{xx}$, gracias a los descuidos que se tienen con la electricidad, elemento indispensable en la casa y en la calle, pero nunca cerca o junto a los retablos"; vid. El churriqueresco en la ciudad de México. México, F.C.E., 1969, p. 56.

2 Carlos Sánchez Navarro "San Ángel (historia, vida y leyendas)", en México en el tiempo. El marco de la capital, t. II, México, 1946, pp. 232 y 252 (ilustración número 23). 
demás y carece de la más elemental sensibilidad para no confundir las ideas con las altas creaciones del arte. $Y$ no obstante que algunos años después, concretamente el 12 de noviembre de 1942, la capilla pudo ser abierta de nueva cuenta al culto -según se lee en una inscripción formada de azulejos-, no hubo forma ya de rescatar el enorme tesoro artístico que ahí se destruyó.

Para resarcirnos de tal pérdida, así sea en una mínima parte, sólo queda el recurso de acudir a las descripciones y apreciaciones que de dicha capilla nos dejaron algunos autores, y mejor aún a las oportunas fotografías que de ella se tomaron entre fines del siglo pasado y principios del presente, tales como las que tomara Antonio Cortés y fueran publicadas en el volumen it de la obra La arquitectura en México, cuyo texto le fuera encargado al arquitecto Federico E. Mariscal. ${ }^{3}$

En base a dichas noticias y reproducciones podemos afirmar que, hasta antes del incendio, la capilla que nos ocupa guardaba uno de los conjuntos más armoniosos y mejor logrados de nuestro arte virreinal que se pudieran encontrar en las poblaciones aledañas a la ciudad de México.

Cabe apuntar que ya Francisco Fernández del Castillo, al escribir la historia del otrora tranquilo pueblo de San Ángel y de sus alrededores hacia la primera década de este siglo, testigo como había sido de turbulentos momentos en nuestro país, se maravillaba que hubiese llegado intacta dicha capilla. De sus retablos comenta: "[son] de los pocos que han podido escapar a la vandálica destrucción que por mil motivos diferentes, y por moros y cristianos, han sufrido nuestros templos, en otros tiempos verdaderas joyas de arte". ${ }^{4}$

Esta capilla se encuentra situada al fondo del brazo izquierdo -o del Evangelio como antes se le designaba- del crucero de la mencionada iglesia de El Carmen de San Ángel. Es de planta de cruz latina techada con bóveda de cañón corrido con lunetos y una cúpula de desplante octogonal en el crucero. Se accede a ella a través de una hermosa por-

3 México. Talleres Gráficos de la Nación, 1923. Huelga decir que dichas reproducciones hoy suman a sus calidades estéticas el mérito de ser documentos históricos de inapreciable valor.

4 Apuntes para la historia de San Ángel, México, 1913, p 70, Y como no le era ajeno el que también por seguir modas estilísticas se cometían graves desacatos, agrega que la capilla estuvo a punto de ser modificada sustancialmente cuando algunas personas trataron "de quitar los altares antiguos para sustituitlos por otros modernos". 
tada barroca labrada en cantera en la que se honra a San Elías, el profeta del Antiguo Testamento que fuera transportado al cielo en un carro de fuego y a quien se considera, precisamente, como fundador de la orden de Nuestra Señora del Monte Carmelo.

Fue construida en 1777 por fray Juan de Santamaria, para que en ella recibiera veneración la imagen de un "Nazareno" que había sido donada a los carmelitas por un particular pocos años atrás.

Dicha imagen había sido hecha por un maestro llamado Pedro el "Clarinero", vecino de Xochimilco, a petición de José Morán, entre el 20 de febrero y el 23 de marzo del año de 1736. Debía su nombre de "Señor de Contreras" al hecho de haberse tomado como modelo otro Nazareno, del que Morán era devoto, y que había sido cedido al convento dominicano de San Jacinto (Tenanitla) por un tal Tomás de Contreras. Sacada con perfección, se bendijo la nueva imagen el Miércoles Santo de dicho año en el obraje que poseía Morán en Panzacola. Tiempo después, deseando éste que recibiese mayor culto, decidió donarla a una iglesia o capilla; mas como no sabía a cuál, organizó una rifa, resultando triunfadora por dos ocasiones la iglesia del colegio carmelitano de San Ángel, verificándose el traslado el 3 de octubre de 1752, razón por la cual también se le conoció como "El señor de la rifa" "Ya ahí su devoción se propagó con gran rapidez, lo que explica que a poco más de 20 años le fuese dedicada la suntuosa capilla a que nos venimos refiriendo. Pronto se le tuvo por muy milagrosa y para mediados del siglo pasado ya habian cobrado gran fama las solemnes festividades, amenizadas con cohetes y repiques, que el pueblo de San Ángel le tributaba cada año el primer domingo del mes de agosto ${ }^{6}$

5 Como para los propósitos de este artículo no es menester detenernos más en la historia de la imagen, remito al lector interesado a las noticias que reunió a tal fin Fernández del Castillo en su obra citada en la nota anterior, p. 70.72.

6 Manuel Rivera Cambas nos informa que a tales fiestas concurrían "todos los habitantes del pueblo y de los circunvecinos, todos los trabajadores de las fábricas... y gran número de familias que dejan la capital"; que en la víspera habia "luces, cohetes corredizos, castillos [y] puestos en que se venden cacahuates, buñuelos, pulque y cenas". (México pintoresco, artistico y monumental, t. $\mathrm{II}$, México, 1882, p. 404.) Por su parte Fernández del Castillo recoge la ingenua tradición de que la imagen era sacada en ese día a la puerta de la iglesia para que viera los fuegos artificiales en su honor; ello no tendria nada de particular, pero ocurre que tal práctica se llevaba a cabo en plena luz del día, pues había que dejar dormir al señor en la noche (op cit., p. 186). Tanto arraigo cobró esta fiesta que se sigue celebrando hasta nuestros días (vid. Virginia Armella de Aspe, "Historia de San 
Volviendo a la capilla, tenemos que eran piezas importantísimas en el rico conjunto ahí integrado, los tres retablos de madera tallada y dorada que se alojaban en el testero y los remates del crucero, mismos que al decir de Francisco de la Maza, eran "de lo mejor que produjo en México el barroco churrigueresco" 7 -de ninguna manera asimila. bles al iplateresco!, como algunos autores los clasificaron-; las cinco grandes pinturas sobre tela guarnecidas por buenos marcos de la época, que se encontraban sobre el arco de la entrada y cubriendo completamente los dos tramos de la nave; 8 los lienzos de las pechinas y otros pequeños cuadros colgados sobre las pilastras y, por último, un vistoso guardapolvo de azulejos.

El retablo principal, de un cuerpo y remate, cubría con su movida planta semihexagonal todo el presbiterio y aun invadía el casquete del cuarto de cúpula. En esto, y en el hecho de quedar estructurado en base a cuatro grandes y finos estípites, se nos presentaba como una resonancia del célebre retablo de Los reyes, en la Catedral Metropolitana, levantado por Jerónimo de Balbás, con la diferencia de que en el del templo carmelitano los espacios interestípites habían ganado en amplitud y mostraban un lenguaje formal y decorativo más evolucionado, evidente en el uso de esa especie de pilastra-nicho y en la plana ornamentación de fina hojarasca.

En la calle central se encontraba, naturalmente, la imagen del "Señor de Contreras", dentro de sobrio nicho o fanal, y encima de éste, iba una magnifica talla del arcángel San Miguel; asimismo, en las calles laterales, debieron lucir cuando menos seis esculturas de santos carme-

Angel", en Artes de México. Ciudad de México No. vir. Sus villas." San Angel y Tlacopac, Año xv, núm. 117, México, 1969, p" 11).

7 op. cit., p. 56

8 El lienzo sobre la puerta representaba la institución del sacramento de la Eu. caristía durante la Ultima Cena, y los grandes óleos de la nave, cuatro momentos de la Pasión de Cristo, los cuales, al decir de Fexnández del Castillo eran: Ecce Homo, La flagelación, El prendimiento y El descendimiento (op. cit., p. 70). Cabe, sin embargo, la posibilidad de una confusión en la identificación de uno de dichos pasajes, toda vez que uno de ellos representaba El calvario, según puede apreciarse en una de las fotografías de Antonio Cortés. Ninguno de los autores que consultamos mencionan si estaban firmadas, pero no hay duda que habria que buscar a su autor entre los pintores de no poca monta que florecieron hacia la segunda mitad del siglo xvir, cercano quizá a Francisco Antonio Maria Vallejo. De estas pinturas nos dice el arquitecto Mariscal que "como obra pictórica son insignificantes pero dan riqueza al conjunto" (op. cit, $, \mathrm{p}, 35)$, en tanto que el propio Fernández del Castillo no dudó en calificarlas "de bastante mérito" (op. cit., p. 70). 


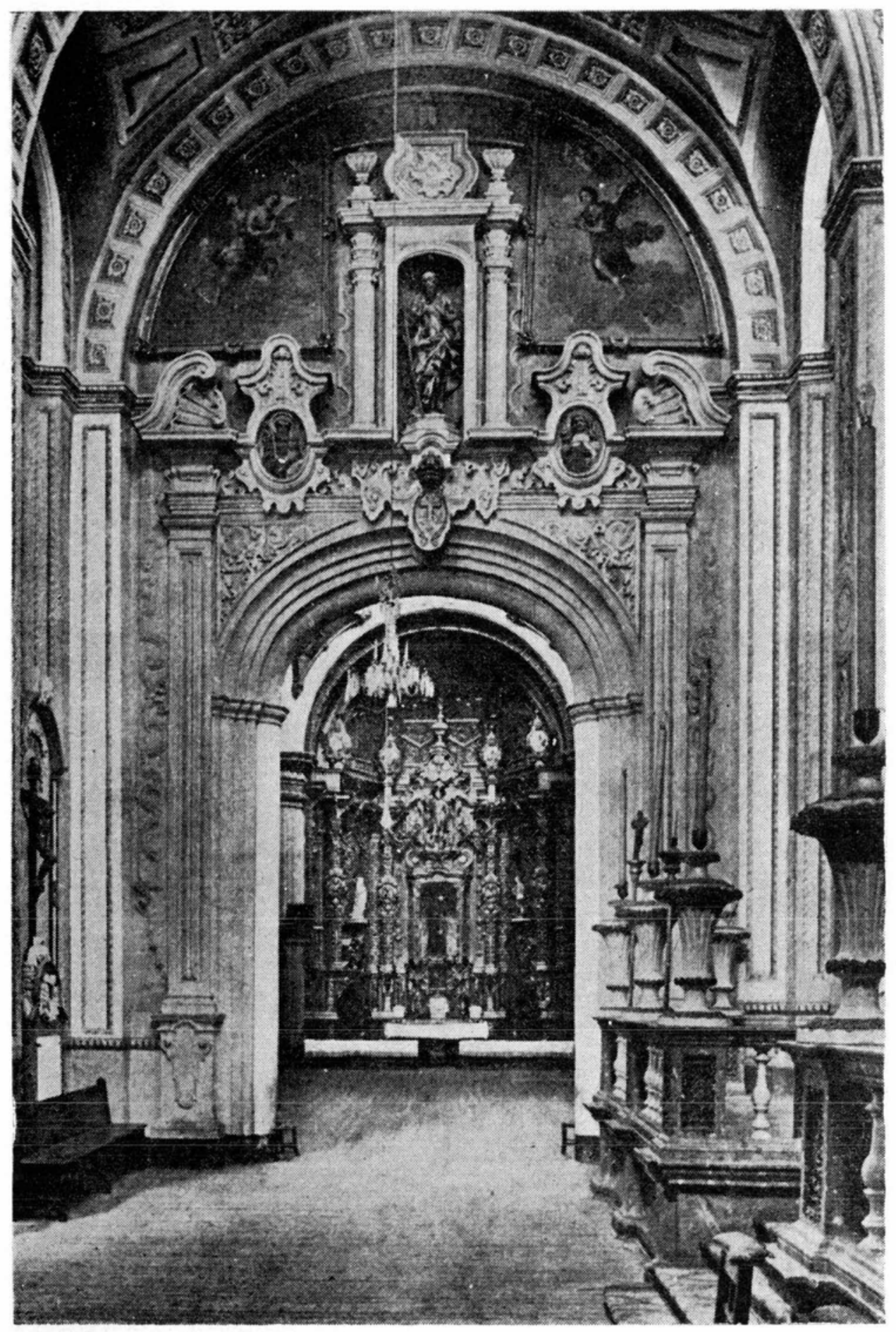

Figura 1. Portada de acceso a la capilla. 


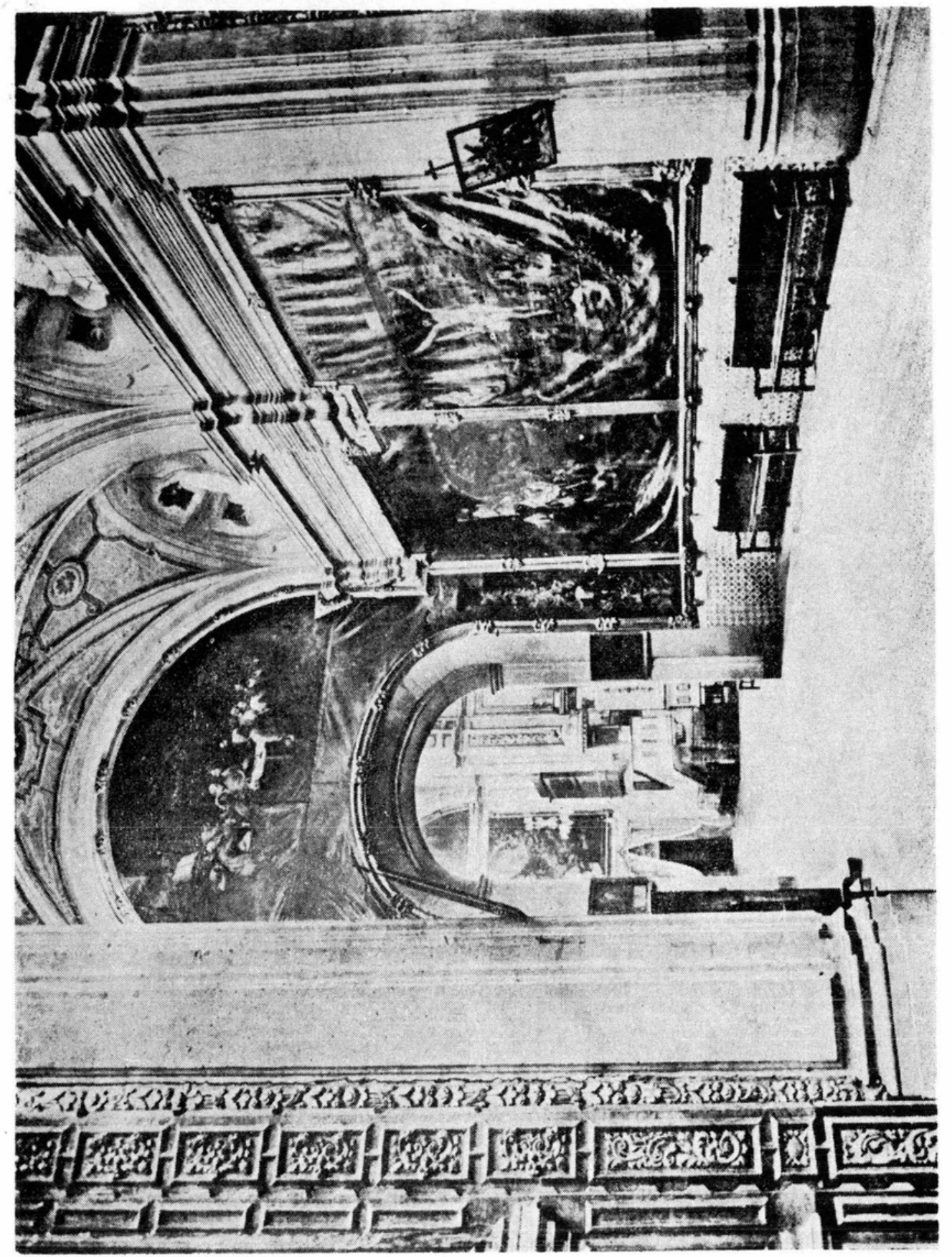




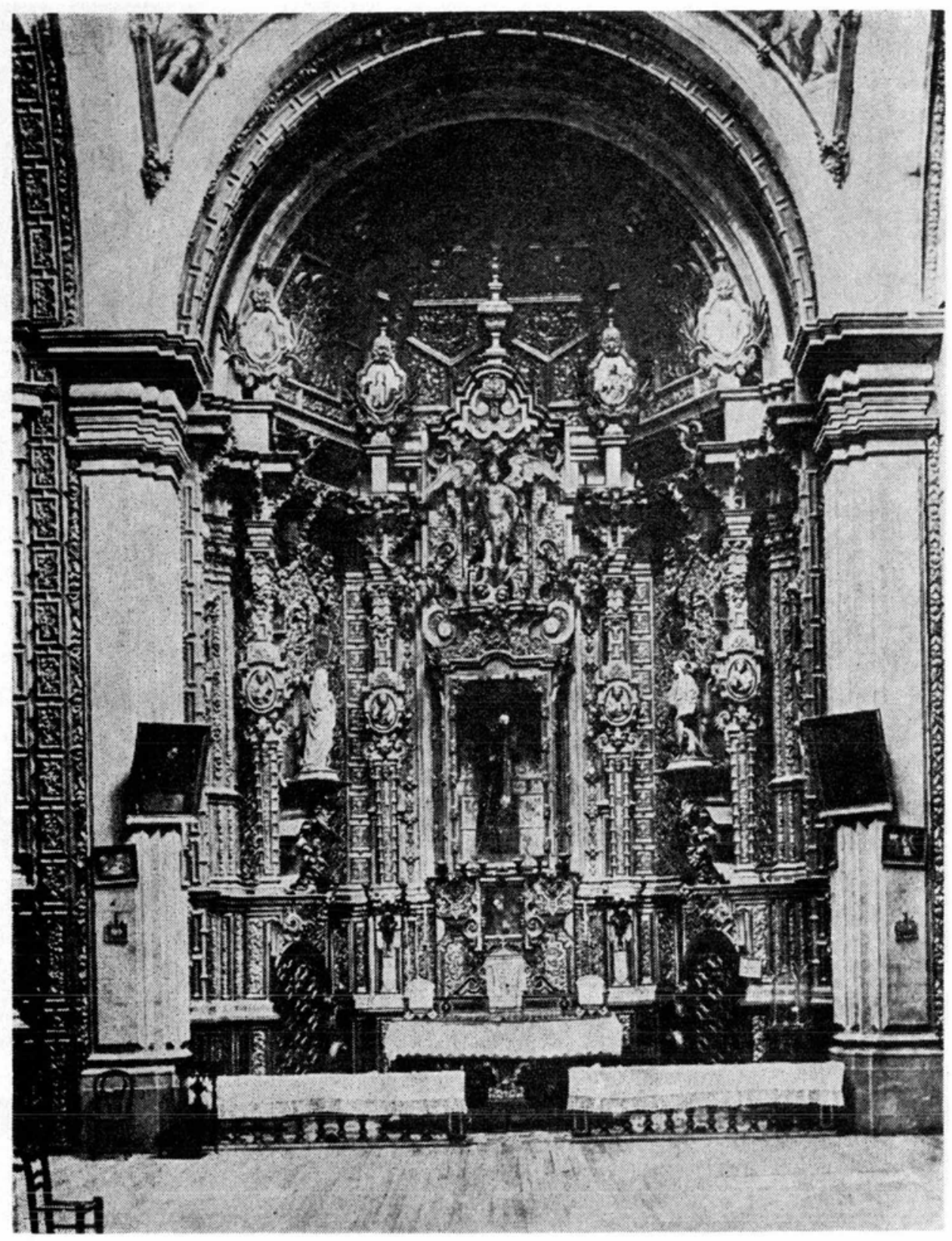

Figura 3. Retablo principal con la imagen del "Señor de Contreras". 
DOI: http://dx.doi.org/10.22201/iie.18703062e.1983.52.1187

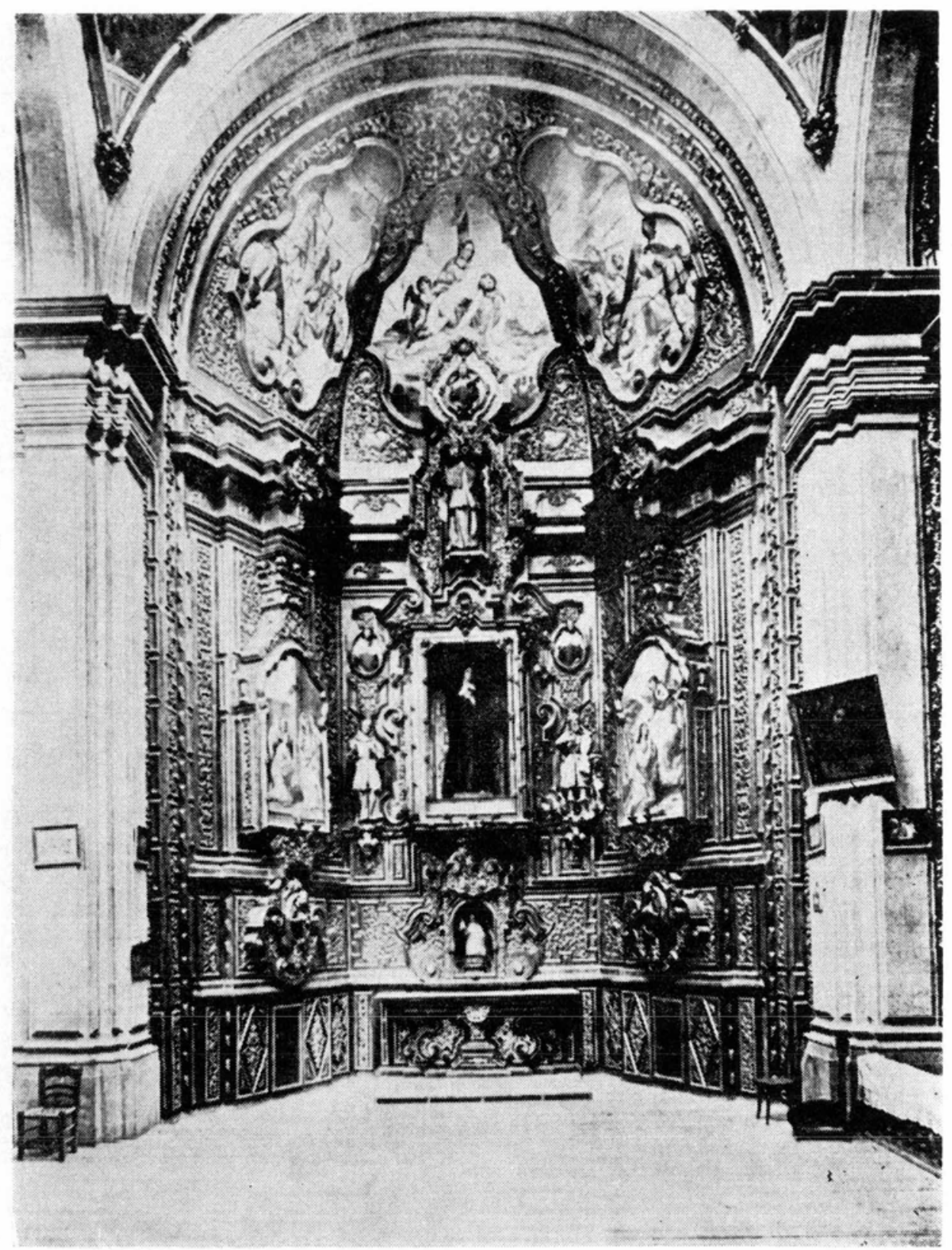

Figura 4. Retablo de la Virgen de los Dolores en el crucero. 
DOI: http://dx.doi.org/10.22201/iie.18703062e.1983.52.1187

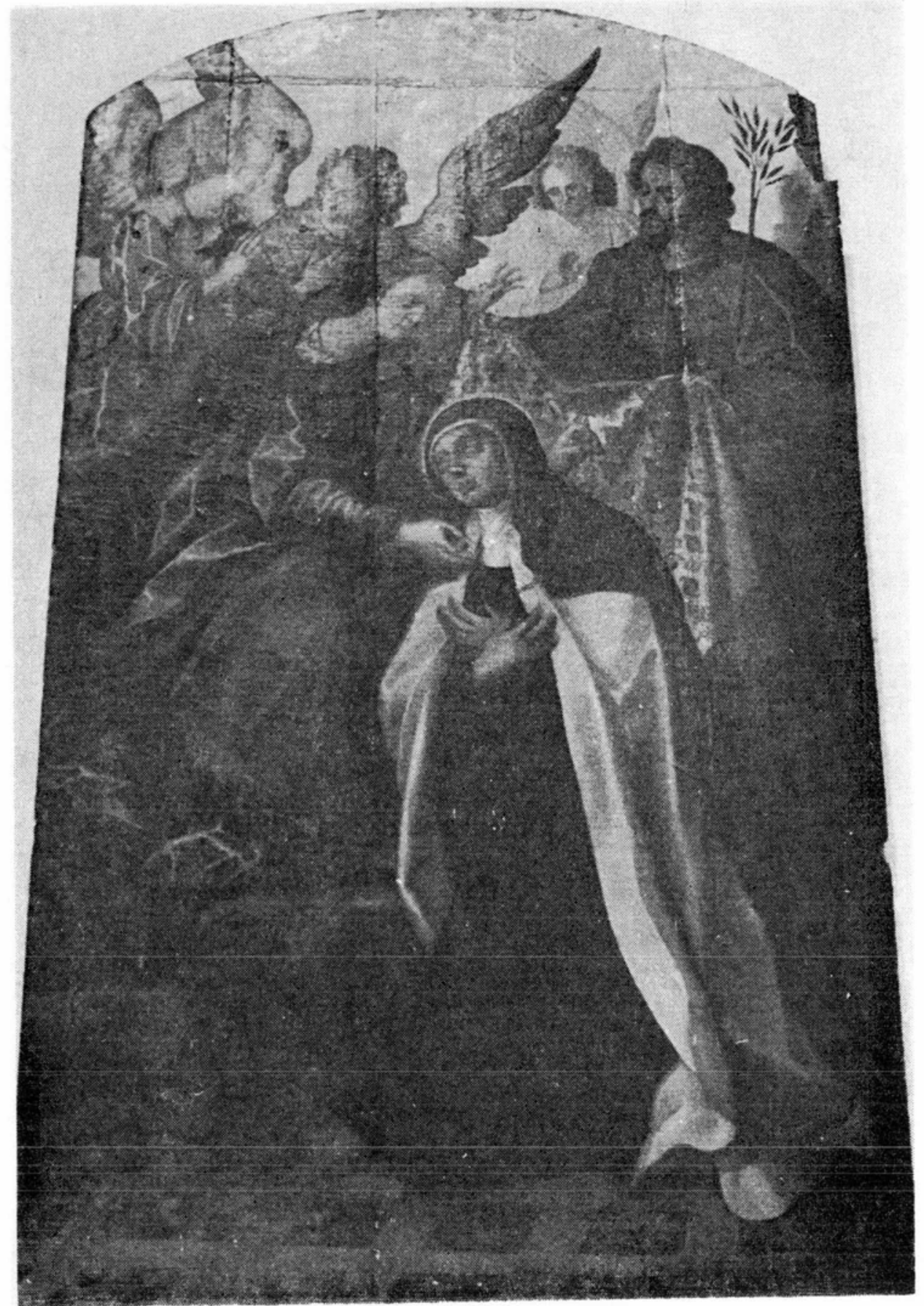

Figura 5. Aparición de la Virgen y San José a Santa Teresa. 
DOI: http://dx.doi.org/10.22201/iie.18703062e.1983.52.1187

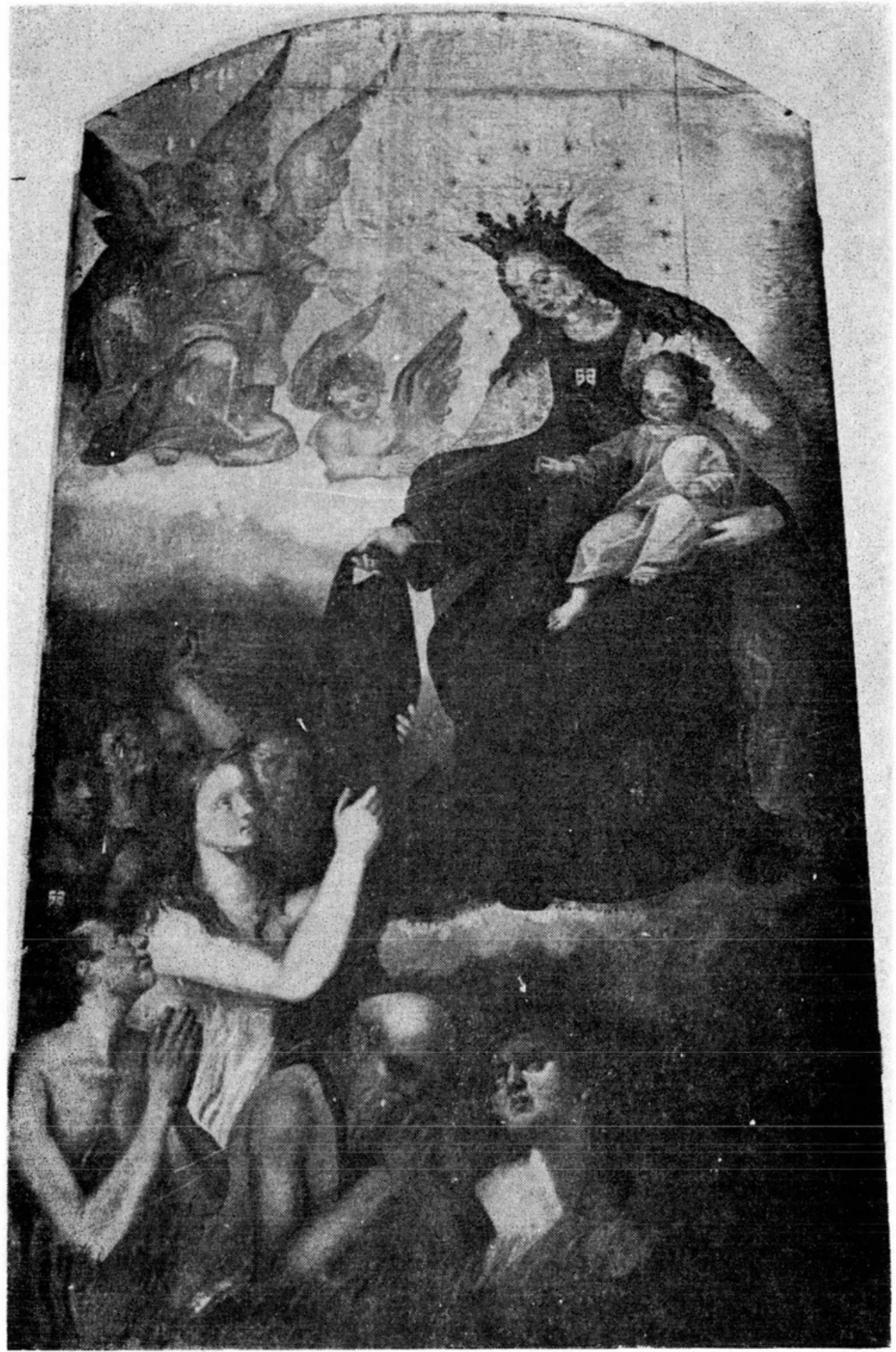

Figura 6. Virgen del Carmen y las ánimas del Purgatorio. 
DOI: http://dx.doi.org/10.22201/iie.18703062e.1983.52.1187

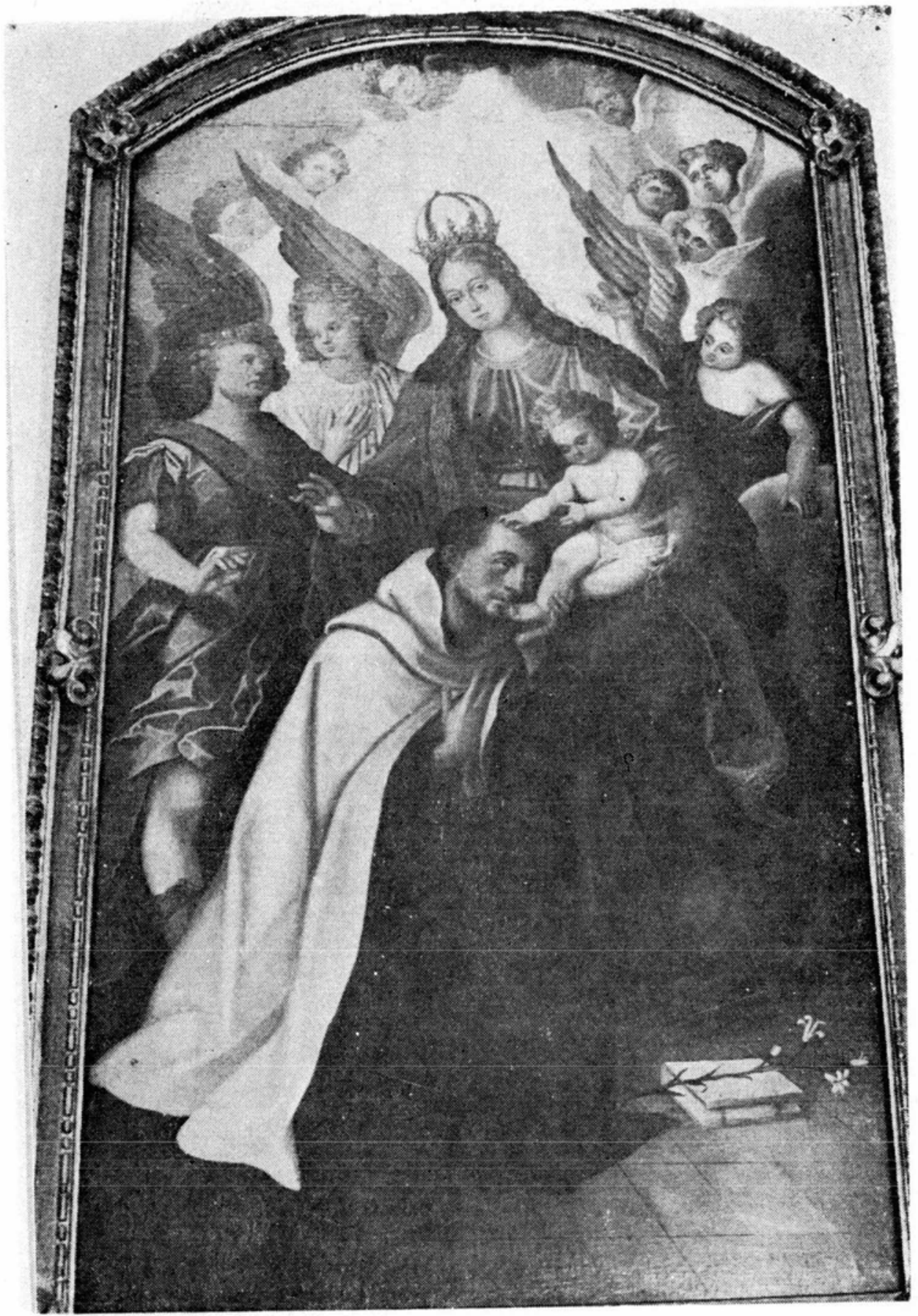

Figura 7. La Virgen y el Niño con San Juan de la Cruz. 
DOI: http://dx.doi.org/10.22201/iie.18703062e.1983.52.1187

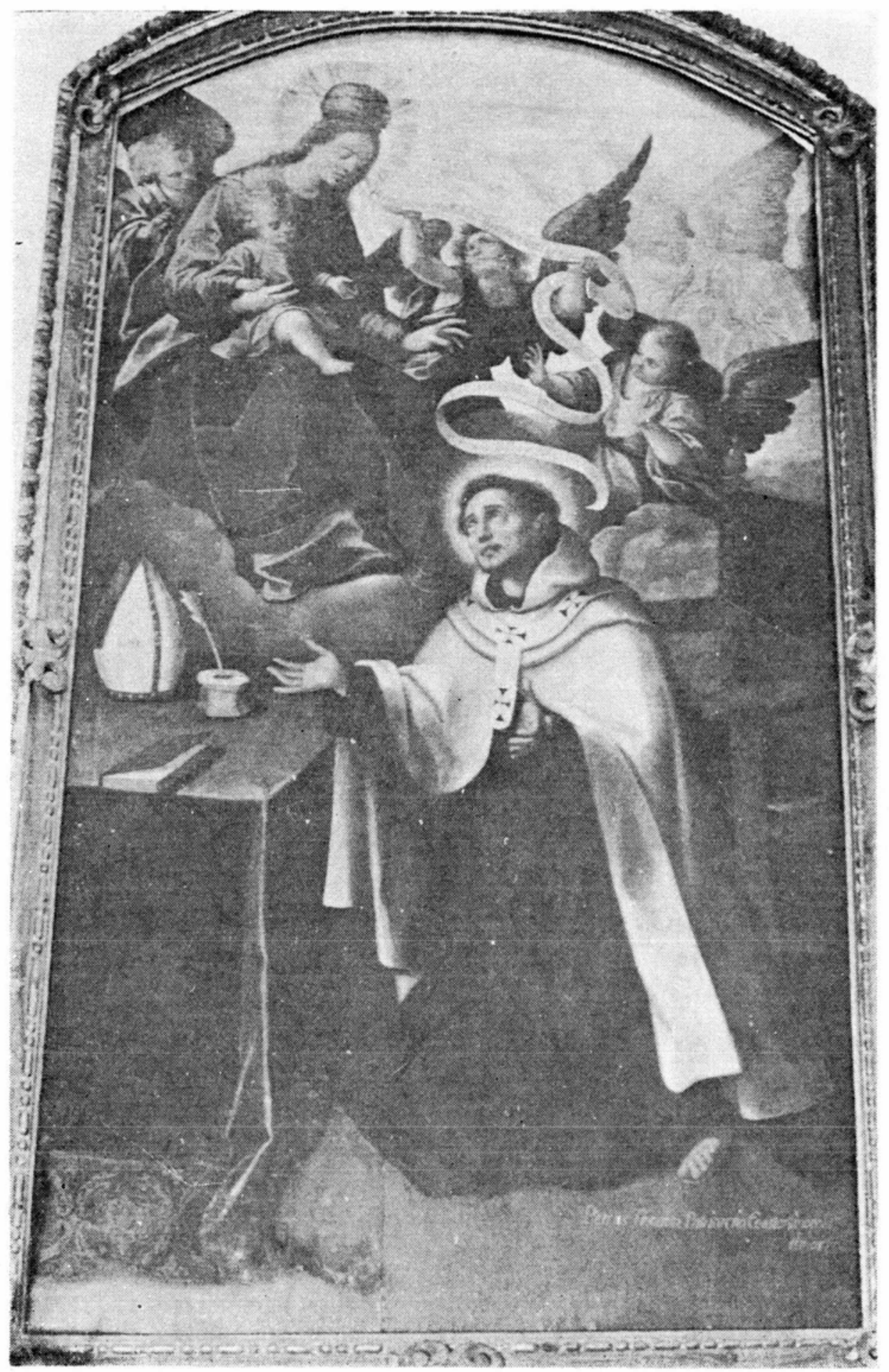

Figura 8. San Pedro Tomás. 
litas. ${ }^{9}$ En los cubos de los estípites se asomaban los bustos de los apóstoles, y en los medallones del remate, había cuatro lienzos dentro de marcos mixtilíneos con los evangelistas. Dicho remate quedaba constituido por tres gajos que cubrían totalmente el cuarto de esfera de la cúpula y presentaba una decoloración de fina hojarasca sobre un diseño geométrico.

Los retablos del crucero eran "anástilos", esto es, carecian de soportes o apoyos y estaban dedicados a La Dolorosa y al señor San José. Al igual que el principal eran ricas estructuras de planta scmihexagonal, de un cuerpo y remate. Curiosamente lucian no esculturas, sino pinturas en los "nichos" de las anchas consolas de las calles laterales, así como también eran pinturas las que, en movidos enmarcamientos, ocupaban la mayor parte de los gajos del remate. Para el primer caso los temas eran de la Pasión de Cristo y, como era de esperarse, sacados de la vida de San José, los del segundo. Cabe sólo agregar que, a juzgar por las fotografías, las pinturas de los tres retablos más parecen a la técnica del temple que al óleo.

$\mathrm{Si}$ me he detenido un poco a recoger algunas de las escasas noticias con que se cuenta en relación a esta capilla es porque, además de que su importancia así lo ameritaba, en la actualidad ahí están expuestas cuatro tablas debidas al exquisito pincel de Luis Juárez, el afamado artista novohispano activo en el primer tercio del siglo xvII, considerado como uno de los últimos y más destacados representantes de la pintura manierista en la Nueva España, y cabeza de una larga y brillante dinastía de pintores que vendría a cerrarse con sus biznietos, Juan y Nicolás Rodríguez Juárez, un siglo más tarde. Lo que sería interesante dilucidar en este caso es si dichas tablas pudieran ser las mismas que de este artista menciona don Manuel Toussaint precisamente en dicha capilla antes del infortunado incendio a que hemos hecho alusión, y que después de ocurrido éste, el mismo Toussaint dio por perdidas.

Mas vayamos por orden. Al ocuparse de Luis Juárez en su imprescin-

9 Nos informa don Francisco de la Maza que, a juzgar por tres fotografías del INAF, se pueden apreciar los caprichos eclesiásticos que hubo de sufrir este retablo, pues mientras que en la más antigua de ellas aparecen seis esculturas de santos carmelitas, para la segunda ya faltan dos, y para la tercera - que corres. ponde a la tomada por Cortés - faltan todas; y nos dice en su punzante y lacónico estilo que se les ha sustituido "por dos imágenes barcelonesas de yeso: una Virgen de Louddes y un San Juan. Sin comentarios" (op. cit., p. 57) 
dible y magna obra sobre la Pintura colonial en México, asentó don Manuel lo siguiente:

Para los conventos carmelitas pintó ... bastantes obras; ... en el convento de esa orden en San Ángel existe buen número de cuadros de nuestro artista, dos a la entrada y otros en la capilla del señor de Burgos; éstos, casi en su mayoría han sido bárbaramente repintados, al grado de que sólo por la vigorosa personalidad del autor pueden ser reconocidos; ...10

Valgan sólo dos aclaraciones antes de continuar. La primera, que este libro, según declaración del propio Toussaint, lo tenía prácticamente terminado desde 1934, pero por razones que no es el caso aquí traer a colación, quedó sin ser publicado hasta el año de 1965, en que, como homenaje póstumo al autor, se le dio a la luz pública. Retengamos, pues, que las líneas transcritas fueron redactadas con anterioridad al atentado que sufrió la capilla que, como ya apuntamos, ocurrió el 13 de agosto de 1935. La segunda aclaración es que don Manuel obviamente se quiso referir a la capilla del Señor de Contreras, pero incurrió en una confusión al llamarla como del Señor de Burgos, advocación, ésta, más asociada a la veneración de la orden franciscana.

Tiempo después, en su igualmente irremplazable Arte colonial en México, publicado en su primera edición en 1948, el mismo Toussaint nos informa que: "En una capilla lateral del templo carmelita de San Angel, en el Distrito Federal, existían varias tablas suyas [de Luis Juárez], aunque bárbaramente retocadas, las cuales fueron destruidas por el fuego."11

Ahora bien, en el primer caso -pese a que se publicó despuésasienta que en la casa de aquella orden en San Ángel existia "buen número de cuadros" de Juárez, pero sólo menciona -y eso sin precisar los temas en ellos representados- dos a la entrada y "otros" en la multicitada capilla. Para el segundo texto es más vago aún, dado que su aseveración consiste en dejarnos saber que en "una" capilla "existían varias tablas suyas", sin precisar tampoco ni número ni temática; nótese que usa el tiempo en pasado: la razón, ya la conocemos: "fueron destruidas por el fuego".

Sin embargo, es necesario hacer notar que, al menos para los pri-

10 México, UNAM, I.I.E, 1965 , p. 98.

11 2a. edición, México, UNAM, I.I.E., 1962, p. 74. 
meros años de este siglo, no parecen haber estado en la multimencionada capilla ninguna de las obras de Juárez, tal y como puede deducirse del estudio de las fotografías obtenidas por Antonio Cortés, mismas que nos entregan desde varios ángulos de vista casi la totalidad del ámbito y del contenido de aquélla, y francamente no sólo no aparecen por ningún lado, sino que incluso no se encuentra espacio alguno para darles cabida. Lo curioso es que si ahí las vio poco tiempo después Toussaint, es porque en algún momento se les colocó ahí y en algún lugar de ella se les encontró acomodo.

Pasemos ahora a hablar de dichas pinturas, mismas que se encuentran colgadas por pares en los ábsides del crucero de aquélla. La primera de ellas reproduce el momento en que la virgen, acompañada del Señor San José y varios ángeles, visten a Santa Teresa con "una ropa de mucha blancura y claridad" y le colocan al cuello una vistosa joya, dándole a entender con ello que quedaba limpia de todos sus pecados y que la apoyarían en sus proyectos. Esta visión, ocurrida en el convento de monjas dominicas de la Asunción, en Avila, nos la relata la propia reformadora carmelitana con las siguientes palabras:

...vínome un arrobamiento tan grande que casi me saco de mí [obligándola a sentarse]... me veía vestir una ropa de mucha blancura y claridad; y al principio no veía quién me la vestía; después ví a Nuestra Señora hacia el lado derecho y a mi padre San Josef al izquierdo, que me vestían aquella ropa...

\section{y continúa:}

Parecíame haberme echado al cuello un collar de oro muy hermoso, asida una cruz a él de mucho valor. Este oro y piedras es tan diferente de lo de acá que no tiene comparación, porque es su hermosura muy diferente de lo que podemos acá imaginar, que no alcanza el entendimiento a entender de lo que era la ropa ni como imaginar el blanco... Era grandísima la hermosura que ví en Nuestra Señora... vestida de blanco con grandísimo resplandor... Al glorioso San Josef no vi tan claro... parecíame Nuestra Señora muy niña. ${ }^{12}$

12 Vida..., cap xxxum. México, UNAM, 1962, p. 232-233. Juárez se ocupó de esta misma visión en otra ocasión. El cuadro en cuestión se encuentra en una capilla de la parroquia de Atlixco, Puebla, pero en tristísimo estado de conservación. Salvo ligeros cambios, tales como la inclusión en la tela de Atlixco de dos angelillos en la parte baja y de otros dos ángeles más, difuminados en el rompimiento de gloria, son prácticamente iguales. 
Ahora bien, es claro que en algunos puntos Juárez se permitió ciertas libertades en la representación del suceso, apartándose de lo descrito por la misma santa, pero ello no altera en lo sustancial el sentido de la visión: Santa Teresa no aparece sentada sino arrodilada, tanto por asi convenir a la plástica como para dotar de mayor unción al portento; la virgen no porta la indumentaria blanca que se cita, sino el manto azul sobre túnica rosa con que se le suele vestir y con que invariablemente Juárez la representó; y en cuanto al manto y collar con que se vio engalanada la santa, si según testimonio de ella misma resultaba imposible siquiera describir las telas y las joyas, no debe extrañarnos que nuestro artista se viera precisado a limitar su fantasía y creatividad, concretándose a insinuar tal riqueza plasmando los lujos que él conocía, con lo cual el celestial manto quedó trasmutado en un hermoso velo estampado que sugiere ostentación, y el collar en una serie de bellísimos engastes de oro, adornados con profusión de perlas, aunque sin la rica cruz a que se refirió la santa.

Pasando a otro punto, tenemos que a fin de reforzar la diagonal que rige la estructura compositiva, misma que desciende de izquierda a derecha, como en la mayoría de los cuadros del artista, así como para dotar de mayor recogimiento a la figura de la santa, aparece ésta devotamente arrodillada, con los brazos cruzados sobre el pecho, la mirada dirigida hacia la virgen y el cuerpo levemente inclinado hacia adelante. La virgen, por su parte, aparece sentada sobre nubes, en posición de tres cuartos perfil derecho, también inclinada con suma delicadeza, para, además de servir de contrapeso a la figura de la santa de Ávila, colocarle en torno al cuello el mencionado collar. Hay que señalar, sin embargo, que en esta representación carece María de esa gracia y suavidad con que Juárez solía representarla; su rostro resulta demasiado redondeado y seca su expresión.

A espaldas de Santa Teresa está el patriarca San José disponiéndose a cubrirla con el mencionado manto. Es, de acuerdo a la tipología del arte novohispano, un hombre joven de gesto amable. Completan la escena tres ángeles; dos de ellos dialogan amistosamente a espaldas de la virgen ${ }^{13}$ y el tercero se asoma detrás de San José. Uno de los pri-

13 Estos ángeles en conversación aparecen en vatias obras de nuestro artista con muy ligeras variantes, vr. gr., en los Desposorios misticos de Santa Catalina (Pinacoteca Virreinal de San Diego, INBA), y por supuesto también en la otra versión de este mismo tema a que acabamos de referimos en la nota anterior. 
meros, el que presenta la torpe solución de aparecer su mano justo por la frente de María, exhibe sus alas abiertas en direcciones opuestas, expediente del que se sirvió Juárez en varias ocasiones y que, como en este caso, acudió a él para dotar de elegancia a la figura y reforzar eficazmente los ejes diagonales que rigen la composición. Respecto al tercer ángel, es tan horrible que cabe incluso pensar si más que deformado por repintes, no se trata de una figura inventada por el restaurador.

Apresurémonos a agregar que todo el cuerpo de Maria está lamentablemente alterado; que los rostros y manos del resto de las figuras fueron repintadas, y que asimismo, hay huellas de intervención en los paños y en el chocante fondo azul de la parte alta. Lo menos alterado y deformado son, además del rostro de Santa Teresa, la cadena del collar y el vistoso velo con que está siendo cubierta; áreas que se salvaron seguramente por lo fino y complicado del trazo, no atreviéndose ahí el anónimo restaurador.

El piso simula un enlosado de mosaico o mármol y también exhibe repintes; insisto en el punto porque ahi, en un recuadro debajo del manto de la santa, se localiza la firma del pintor. Esto y lo extraño de su caligrafía nos hace pensar que dicha rúbrica también ha sido sobrepuesta, para reponer seguramente la original. De cualquier manera, no necesitábamos de ella para identificar esta tabla, y las tres restantes, como de Juárez. Lamentamos los retoques y alteraciones, pero no hay duda de que, concretamente esta tabla, era una buena muestra del arte de Luis Juárez. Consignemos, por último, que presenta una banda negra en el borde inferior. Ignoro si para ocultar algo (acaso una inscripción) o si tiene algún significado.

El segundo cuadro representa a La Virgen del Carmen con las ánimas del Purgatorio; de las cuatro tablas es, sin duda, la que más deformada está por los repintes.

- Aparece la virgen con el Niño Jesús alargando un escapulario a las ánimas del purgatorio que ocupan la parte inferior de la composición. El Niño Jesús no está desnudo como en la mayoría de las ocasiones, sino vestido con una túnica azul y sostiene un globo u orbe transparente en una mano y una crucecita de oro en la otra. Pese a que sus piernitas presentan un suave movimiento, una ligeramente más recogida que la otra, pero las dos hacia el frente, se siente algo rígida y seca su figura. 
María luce el pelo suelto sobre sus hombros, lleva una corona -bas. tante más ligera que otras con que gustó pintarla nuestro artista- y un vivo resplandor y trece estrellas le circundan la cabeza. A pesar de los repintes se observa que Juárez había trabajado con deleite y esmero su manto y más aún la orla del escapulario, en el que aún se aprecia el rico trabajo de encajes y brocados. Y, aunque los rostros de madre e hijo todavía conservan esa dulzura típica de Juárez, es de lamentar que estén tan alterados, pues la verdad es que resultan francamente desagradables con esa tez tan lechosa que se aviva más por esas horrendas mejillas sonrojadas. En el ángulo superior izquierdo vemos dos ángeles en amena charla que debieron ser hermosísimos a juzgar por lo agradable de sus posturas y la exquisita delicadeza y transparencia con que Juárez los plasmó; en mala hora intentó "componerlos" el quizá bien intencionado cuanto incapaz restaurador. Del otro angelillo que se asoma junto a los anteriores, prefiero no hablar.

En la parte baja se agrupan varias figuras desnudas, vistas de busto, entre las que destaca la de una mujer que recibe con avidez y esperanza el escapulario que le tiende la Virgen; su piel, más blanca que las demás, quizá indique que ha quedado limpia de sus faltas y ha alcanzado la pureza necesaria para pasar al cielo. En el ángulo izquierdo también resalta un hombre de tres cuartos con el rostro de perfil que junta piadosamente las manos implorando misericordia; ${ }^{14}$ sin duda es una conmovedora figura, como también lo es la del anciano que está junto a él, sumido en sincero arrepentimiento. No es necesario insistir en que esta zona exhibe muchos repintes, de suerte tal que poco es lo que nos permiten ver de Juárez.

El cuadro queda estructurado en base a un eje diagonal que sube de izquierda a derecha, esto es a la inversa de como solía Juárez trabajar. Ello puede explicarse arguyendo que así se lo sugirió la estampa que tomó como modelo, pero más aún por responder a una necesidad de variación y de equilibrio, ya que como hemos dicho con toda seguridad hacía juego con otras pinturas, dentro de la unidad mayor de un retablo.

14 La postura y expresión de su rostro no puede menos que hacernos recordar al del San Juan Evangelista que aparece en el cuadro de La ascensión de Cristo (Museo Regional de Querétaro, INAH), y al del San José de La presentación de Jesús al templo (Museo Regional de Guadalupe, Zacatecas, INAH), del mismo Juárez. 
El tercer cuadro supongo que representa una visita de la virgen y el niño, a San Juan de la Cruz. La escena no puede ser más tierna ya que nos muestra a un religioso carmelita, en el momento de besar respetuosamente el pie del Niño Jesús, quien, sentado en las piernas de su madre, le corresponde con tiernas caricias. ${ }^{15}$ María, sentada sobre nubes, aparece en inusual disposición frontal, lo que obliga a que el grupo principal quede inscrito dentro de un triángulo irregular cuyo vértice viene a quedar sobre su cabeza.

El cuadro no es ni con mucho de lo mejor de Juárez, y acaso haya que culpar al restaurador de las incorrecciones en el dibujo y de la frialdad e inexpresividad de los rostros, ya que, por ejemplo, pese a las facciones dulces y juveniles en el de María, la verdad es que queda muy lejos de los rasgos estereotipados y acentuadamente infantiles a que nos tiene acostumbrados Juárez.

El niño Jesús es un cándido infante cubierto tan sólo con un tenue cendal, y es una lástima que a causa de los repintes no podamos disfrutar del suave modelado de sus carnes. Su postura resulta muy similar a la que guarda el Niño Jesús representado en el cuadro anterior y en el de Los desposorios misticos de Santa Catalina (Pinacoteca Virreinal de San Diego, INBA), no obstante que aquí está plasmado en la dirección contraria y queda ahora oculto un pic. Vemos, pues, cómo Juárez, si bien repetía una y otra vez sus gestos, posturas y composiciones, casi siempre encontraba la manera de hacerlas variadas.

Hemos identificado al religioso carmelita que recibe tan bienaventurada visita y recibe la gracia de poder besar el pie del Niño Jesús y recibir sus caricias, con San Juan de la Cruz; pero estsá realmente este santo? Adviértase -al igual que en el cuadro con este mismo asunto en Morelia- que la cabeza del personaje no despide resplandor al." guno; asimismo, el libro y la azucena que vemos en el piso, son atributos tan impersonales que perfectamente pueden aplicarse a cualquier otro varón de dicha congregación que se hubiese distinguido por la pureza de sus escritos. Con todo, no creo sea demasiado erróneo pensar que se trata de San Juan de la Cruz, máxime si recordamos que no fue sino hasta principios del siglo xvin en que éste fue canonizado, lo que

15 No fue tampoco la única ocasión en que Juárez se ocupó de este tema, pues en la iglesia del que fuera convento del Carmen en la ciudad de Morelia, se localiza otra versión, aunque con notables diferencias; desafortunadamente está colgada a tan gran altura, que se dificulta su estudio. 
de paso explicaría el que Juárez le representara aun sin aureola, reservada generalmente a los ya consagrados.

$\mathrm{Su}$ rostro deformado por los repites, no alcanza a expresar esa profunda vida interior o beatífico estado con que Juárez animaba a sus personajes en éxtasis; sin embargo, y pese a lo estereotipado de sus facciones, nos permite captar el espíritu transparente de su autor y su inclinado espiritu al misticismo.

Hacia el lado izquierdo encontramos dos ángeles en poses teatrales que igualmente aparecen en otras pinturas del autor; el primero es una gallarda figura que eleva devotamente el rostro y extiende su brazo con gran elegancia, mostrando una mano en escorzo muy del gusto de Juárez. Más bella es la figura del segundo ángel, ligeramente más atrás con la mano sobre el pecho, por la serenidad de su actitud y la ternura de su mirada. Del lado opuesto, atrás de María, otro ángel que, por la manera de vestir y levantar el brazo, nos recuerda al arcángel San Gabriel de La Anunciación y al Angel de la Guarda (Pinacoteca Virreinal de San Diego, INBA), pero debemos apresurarnos a decir que ni con mucho les iguala en belleza, si bien de nueva cuenta debiéramos achacar la culpa al torpe autor de los repintes, que lo deforman; de igual manera los horrendos querubines que se asoman entre nubes, acaso no sólo fueron "compuestos" sino hasta inventados por aquél.

El último cuadro representa a San Pedro Tomás; la tabla nos lo muestra vestido con el hábito carmelita y un palio, recibiendo la visita de la virgen y el Niño Jesús. Este santo, originario de Aquitania, profesó en la orden de Nuestra Señora del Monte Carmelo, donde se distinguió por sus virtudes y sabiduría al enseñar filosofía en varios conventos de la orden. Desempeñó los oficios de nuncio y de legado apostólico por espacio de 12 años, hasta que en 1354 fue nombrado obispo y luego arzobispo de Creta, y en 1364 designado patriarca de Constantinopla. Fue un acérrimo defensor de la Inmaculada Concepción de María y se sostiene que por ello recibió grandes favores de la virgen. Murió en Chipre el 6 de enero de $1366 .^{16}$

La actitud del santo es típica de nuestro artista, al grado de que podría decirse que, por mencionar dos casos, repite la postura del San Ildefonso en la tabla que le representa recibiendo la casulla de manos de la virgen o de Cristo en la tabla de La oración en el huerto (Pina-

16 Enciclopedia Universal Ilustrada, Barcelona, Espasa-Calpe, S.A., t. 43, p 1298 
coteca Virreinal de San Diego, INBA) : arrodillado de tres cuartos perfil izquierdo. rostro ligeramente inclinado, mirada dirigida hacia lo alto, los brazos extendidos hacia adelante a la altura del pecho y las manos nerviosas y en gesto suplicante.

En el delicioso grupo de la virgen con el niño podemos constatar esa suavidad que Juárez lograba comunicar a sus figuras Curiosamente también aquí el Niño Jesús viste una túnica azulosa. Está sentado sobre la pierna de su madre y extiende tiernamente su mano hacia el santo, al tiempo que le brinda una dulce mirada. Maria, sentada sobre nubes, luce una pesada corona. Su rostro, éste sí, tan del gusto de Juárez, nos presenta a una dulce joven de limpias facciones, cuyo pelo, cubierto por un velo transparente, se desliza suavemente sobre la espalda. De agradable efecto y trabajado con propiedad es el halo azuloso y el brillante resplandor de rayos amarillos que despide su cabeza. Para transmitir la idea de que la virgen está hablando y enterarnos de lo que ha expresado, Juárez ha empleado la arcaica solución de la filacteria; de suerte tal que frente a ella un ángel sostiene una larga banda con una inscripción (extrañamente en español y no en latín) que reza: "Permanecerá esta Religió(n) del Carmen hasta el fin del mundo, porque han de saber q (ue) el profeta Elías su fundador, cuando se halló presente a la Transfiguración de mi hijo le rogó lo mismo i lo alcanzó con sus oraciones."

Cabe advertir que dicho ángel recuerda vivamente al que aparece en el cuadro de El martirio de San Aproniano de Baltasar de Echave Orio, sosteniendo igualmente una filacteria (Pinacoteca Virreinal de San Diego, INBA), lo que nos permite apreciar las relaciones e influencias que había entre los artistas novohispanos, fenómeno lógico y necesario dado el ambiente tan cerrado que privaba en dicho medio.

A espaldas del santo vemos un sillón frailero de respaldo y banco forrado con un paño verde que hace juego con el mantel que cubre la mesita que le queda enfrente, sobre la cual encontramos una mitra, un libro y un tintero, elementos que nos recuerdan su dignidad eclesiástica y el valor de sus escritos.

De excelente factura es la cabeza del santo, rodeada de un vivo resplandor, construida en base a recetas bien aprendidas y de probado éxito, como son la mirada casi en blanco, ojos rehundidos con párpados bien sombreados, nariz recta y ancha vigorosamente trabajada, boca entreabierta, encarnación grisácea en torno a ella a manera de 
bozo o incipiente barba y un eficaz modelado. En resumen, se trata de un rostro característico de nuestro artista que, pese a la refinada idealización que exhibe, y a lo estereotipado de su expresión podemos convenir que resulta de gran verismo y no está exento de vida, dramatismo y unción.

Respecto a los ángeles que aparecen en la escena, es necesario repetir que están un poco deformados, pero afortunadamente aún se reconoce en ellos la suavidad del pincel de Juárez, amén de que repiten dibujo, posición y facciones de algunos otros que pudiéramos encontrar a lo largo de su copiosa producción. Por último, en esta tabla podemos apreciar cómo Juárez supo sacar provecho de ese gustado expediente suyo de desvanecer las figuras de los ángeles que se encuentran próximos a las entradas de la gloria, para acentuar más aún su incorporidad.

Antes de terminar no estaria de más apuntar algunas generalidades en torno al lenguaje plástico empleado en estas obras por Juárez. Para empezar, exhiben un dibujo correcto pero no excesivamente pulido, así como también un aceptable, aunque moderado, juego de luces y sombras. El tratamiento de las telas es, en términos generales, convincente, pero se advierte en algunas ese aspecto acartonado tan propio de la época; del mismo modo se observa en ellas (como casi en el resto de la producción de este artista) ese recurso tan manierista -de ascendencia veneciana- de los reflejos o brillos metálicos, y que en algunos casos llega a ser un auténtico chisporroteo eléctrico. Por lo que respecta al colorido, poco es lo que podemos decir pues está sumamente alterado; empero, se antoja animado y bien contrastado a excepción del cuadro de las ánimas del Purgatorio, en que resulta de un cromatismo no poco frío y monótono. Y en lo que toca a la composición, no resta sino recordar que Juárez empleó con buen tino ejes diagonales en la estructura interna de estos cuadros, tanto para dotar de cierto dinamismo a las escenas, como para conectar eficazmente el mundo tangible con el divino.

En resumen, con todo y que, como hemos insistido a lo largo de estas líneas, las cuatro tablas evidencian los estragos de una torpe restauración $-\mathrm{y}$ recuérdese que ya don Manuel Toussaint expresaba que los cuadros que vio de Juárez en esta capilla estaban "bárbaramente repintados"- no hay duda de que son de este artista pero están tan alteradas que ciertamente, de no ser la composición, algunas solucio- 
nes y aislados trazos, poco es lo que realmente nos dejan ver de su exquisito pincel.

Por último, en el estado actual que guardan nuestros conocimientos, no hay forma de asegurar si estas cuatro pinturas que hoy día se encuentran en la renovada capilla del "Señor de Contreras", sean aquellas de que hablaba Toussaint, o se trata de otras. ${ }^{17}$ Lo que sí podemos afirmar es que forman parte de una misma serie -acaso restos de un mismo retablo, ¿por qué no?, hecho para el convento carmelita de San Ángel-, toda vez que comparten varias notas en común, como son el que las cuatro pinturas sean sobre tabla, presenten la misma forma rectangular que cierra en la parte superior en un arco rebajado, tengan medidas semejantes, $2.30 \times 1.30 \mathrm{~m}$, y presenten una misma temática, pues no obstante que están representados asuntos y personajes diferentes, todos pertenecen a la orden de Nuestra Señora del Carmen, orden para la cual, tal y como apuntara Toussaint, parece que Juárez trabajó bastante.

17 Sobre el particular conviene no olvidar que ya el propio don Manuel hablaba de que en ese convento paraba "buen número" de obras de Juárez, noticia importante pero igualmente llena de vaguedad - pues ¿qué cantidad significaba para don Manuel "buen número"? _, que, sin embargo nos permite inferir que acaso eran más de cuatro. Por otra parte nadie en la iglesia recuerda desde cuándo están colgadas las tablas que ahora nos ocupan ni su paradero anterior. 